\title{
Online Purchase Intention Among School Teachers: Extension of Technology Acceptance Model (TAM)
}

\author{
Zuraidah Zainol, Roihan Yazit, Thuraiya Zakaria, Nurul Fadly Habidin \\ \& Juliana Osman \\ Faculty of Management \& Economics \\ Universiti Pendidikan Sultan Idris \\ 35900 Tanjong Malim, Perak, Malaysia \\ Email: zuraidah@fpe.upsi.edu.my \\ DOI: https://doi.org/10.37134/jcit.vol7.9.2017
}

\begin{abstract}
In recent years, the Malaysian teachers market makes such a compelling and profitable demographic segment for online business. However, little research has attempted to examine the purchase attitude and behaviour of the teachers. Thus, using the extended Technology Acceptance Model (TAM), this study aims to investigate the effect of perceived usefulness, perceived ease of use, perceived reputation, perceived security and perceived privacy on teachers' trust and consequently on teachers' online purchase intention. This study adopted quantitative approach. Data obtained from a sample of 150 teachers using a self-administered questionnaire, were analysed using Multiple Regression Analysis. The results reveal the perceived ease of use, perceived security and perceived privacy as significant predictors of online trust among teachers, and online trust positively affect the online purchase intention. The results provide empirical evidence on the role of additional constructs and applicability of the extended TAM. The results also offer valuable insights to marketers on how to better serve the huge market of teachers and induce them to purchase online.
\end{abstract}

Keywords Online trust, online purchase intention, Technology Acceptance Model, teachers

\section{Research Background}

In line with the rapid development of the internet, sellers worldwide have taken the opportunity to use the internet as a medium to promote and sell their products to the local as well as the global market. With more and more products are sold online, customers can easily shift from traditional to online shopping that offer the customers with many advantages, including a wider selection of products, escape from traffic jams, shop at customers' convenience (Leng and Zhang, 2012). In relation to that, the number of online consumers has increased significantly worldwide, and there is no exception for Malaysia (Nadaraj, 2013). In 2010, it was reported that the Malaysia's market of online shoppers worth RM1.8 billion, and expected to grow to RM5 billion in 2014. More importantly, Malaysia had turned out to be among the top three countries in Asia with highest online spending (Ministry of Finance Malaysia 2014). Furthermore, it has been deemed that the involvement of Malaysian in online shopping is very encouraging and phenomenal, that in 2012, the statistics showed that Malaysian shoppers had spent almost US\$354 online (Nadaraj, 2013; Bernama, 2014). Besides, the delivery of product purchased online made by Pos Malaysia had increased dramatically from 29 million in 2011 to 40 million in 2013 (Bernama, 2014).

The increase in the online sales and purchases play a major role towards the development of the nation and world economy. A study by McKindsey (2010) indicated that the transaction via the internet has contributed around 4.1 percent or RM29.64 billion to the Malaysia Gross Domestic Product (GDP), placing Malaysia among the 30 fastest-growing countries where the 
internet has great potential to transform the economy (Ministry of Finance Malaysia 2014).

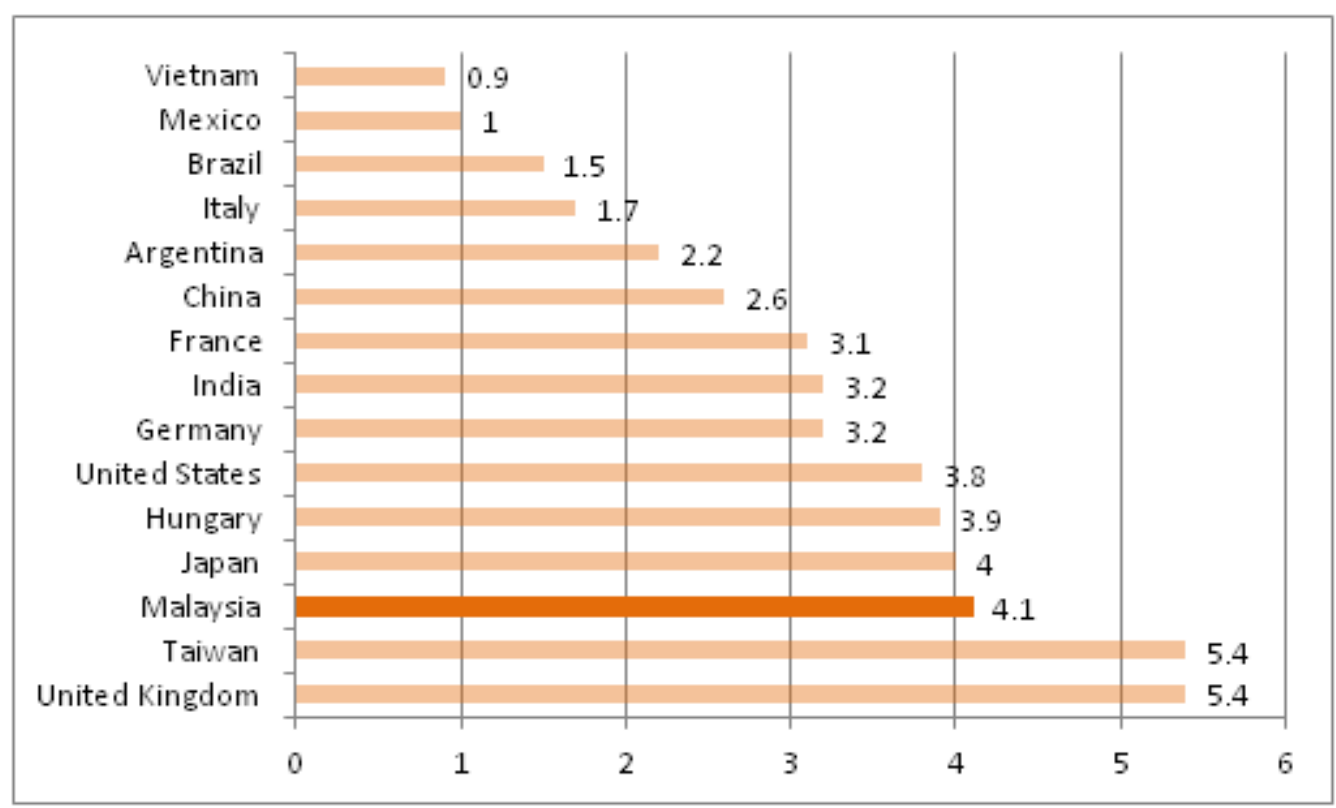

Figure 1 iGDP Index Rank (\% Contribution to GDP)

Source: Ministry of Finance Malaysia (2014)

In Malaysia, teacher is considered as among the largest workforce group. Referring to the statistics released by Education Management Information System (EMiS), as depicted in Table 1 , the total number of primary and secondary school teachers is 238,073 and 181,747 , respectively. Taken as a whole, the number of teachers in Malaysia amounted to 419,820 , signifying a huge market of teachers.

Table 1 Number of Primary and Secondary School Teachers

\begin{tabular}{lccc}
\hline \multirow{2}{*}{ Levels } & \multicolumn{3}{c}{ Frequency } \\
\cline { 2 - 4 } & Male & Female & Total \\
\hline Primary school & 71,523 & 166,550 & 238,073 \\
Secondary school & 55,076 & 126,671 & 181,747 \\
\hline Total & 126,599 & 293,221 & 419,820 \\
\hline
\end{tabular}

Source: Data Education Management Information System (EMiS) (2014)

Compared to other types of career, teachers appear to have more leisure time. Based on the databases of Education Management Information System (EMIS) of the Ministry of Education (2014), teachers relatively spent about 2.4 to 2.9 hours a day for teaching and learning session. Besides, teachers enjoy long school holiday and attractive leave conditions. Due to shorter teaching hours and longer school holidays, teachers are more likely to have more time to hang out online, including to shop online.

In addition, teaching is considered as a stable career with strong job guarantees among Malaysian. Figure 2 illustrated the starting salary for selected occupation. Compared to other occupation, the starting salary of teachers is considerably high. Thus, their spending power 
can be considered as high that will enable them to become profitable-to-serve market.

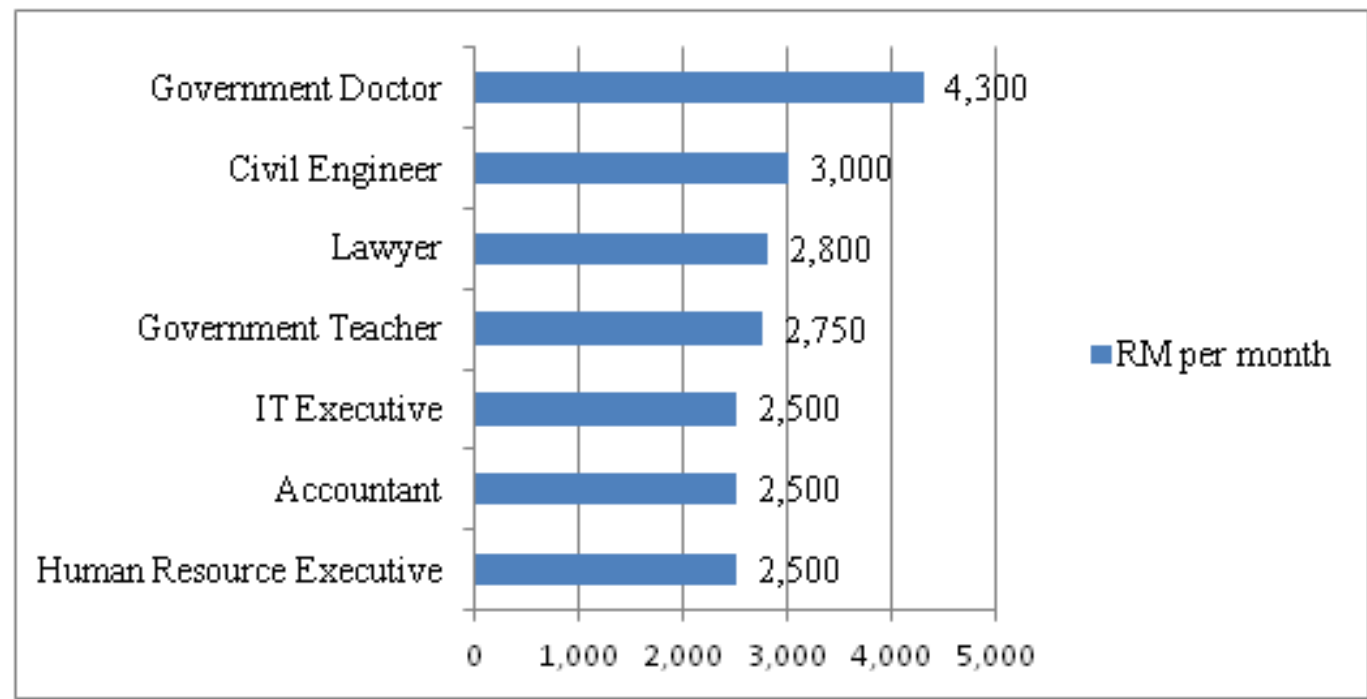

Figure 2 The Starting Salary Selected Professions in Malaysia in 2010

Teachers in Malaysia also have a wider opportunity to earn additional income, particularly by running extra classes or tuition. The demand for tuition classes increases tremendously due to the changes in the economic and social status. As a matter of fact, many Malaysian parents are willing to pay more to ensure their children get the best education, to the extent that the expenses for extra classes are higher, far beyond the school fees. According to statistics released by the Malaysian Tutors Consultancy (MTC) (2015) in Table 2, the tuition rates for primary school students in Malaysia is extremely expensive. Accordingly, with a lot of extra income, teachers have a high purchasing power and are capable to create demand. Thus, teachers apparently appear as a profitable segment to serve by online sellers.

Table 2 Malaysia Tuition Rates

\begin{tabular}{llll}
\hline & \multicolumn{1}{c}{ General Tutors } & \multicolumn{1}{c}{ Specialist Tutors } & \multicolumn{1}{c}{ Premium Tutors } \\
\hline Experience & $\begin{array}{l}\text { Having at least 1-3 years of } \\
\text { tutoring experience }\end{array}$ & $\begin{array}{l}\text { With more than 5 years of } \\
\text { teaching experience }\end{array}$ & $\begin{array}{l}\text { Accumulating for at least 7 } \\
\text { years of tutoring/teaching } \\
\text { experience }\end{array}$ \\
Standard 1-3 & RM28-40/hour & RM30-46/hour & RM40-62/hour \\
Standard 4-5 & RM30-46/hour & RM32-52/hour & RM41-68/hour \\
UPSR & RM32-52/hour & RM35-60/hour & RM45-75/hour \\
\hline Source: Malaysia Tutors Consultancy (2015) & &
\end{tabular}

Moreover, the rapid innovations of information communication technologies (ICTs) have transformed teaching, learning and research experience in the education field. In particular, to align with the development of ICTs, all teachers are encouraged to ICT such as multimedia, interactive internet and web-based electronic tools in the teaching and learning process (Chai, Hong, and Ching, 2010). Due to that, teachers turned out to be IT-literates. By becoming ITliterates, teachers possess a high potential to become a customer of an online business.

In that regards, teachers serve as a compelling potential market for online business. To be successful in online business, it is vitally important for online sellers to acquire a clear insight on the attitude and behaviour of teachers in order to induce them to purchase online. 


\section{Problem Statement}

In understanding the customer attitude and behaviour toward online shopping, much research has adapted Technology Acceptance Model (TAM) (Li and Huang, 2009; Umair et al. 2012; Rapidah et al., 2014). In particular, Li and Huang (2009) showed the significant role of perceived risk to affect the intention to purchase online. Another study by Hossein, Seyede and Faeze (2011) revealed perceived enjoyment, perceived usefulness, firm reputation and social influence as significant predictors of consumer online purchase intentions. In addition, recent findings demonstrated the significant effect of trust on the purchase intention (Seyed, Amir, and Saeed, 2011). Thus, in order to investigate the online purchase intention, it is critical to extend the standard TAM by including other significant constructs, particularly perceived usefulness, perceived ease of use, perceived reputation, perceived security and perceived privacy.

In Malaysia, a few studies have tackled the issues of online shopping. A study by Jasman, Osman and Ramayah (2005) using TAM and Theory of Planned Behavior (TPB) to compare intention to purchase online among internet users in Indonesia, Malaysia and Singapore. Lim and Ting (2012) have conducted a study in shopping malls within Klang Valley, Malaysia to understand how consumers form their attitudes and enhance online shopping intentions, despite the significant result obtained in the study the authors find out the TAM needs to be extended to include other belief constructs. Furthermore, the influence of demographics was not covered in this study, thus research only presented the demographic characteristics of Malaysians. According to Marzieh, Laily, Jamil and Syuhaily (2011) online sellers need to improve their performance by emphasizing integrity and ability which in turn encourage consumer purchasing behaviors.

Although excessive studies have been conducted to investigate the consumer behavior toward online purchasing in Malaysia, little research has paid explicit attention on the teacher's online shopping intention. Given that teachers represent a huge market for online products (Ministry of Education (EMIS), 2014), it seems critical for this study to extend the TAM model and investigate the effect of the antecedents of trust and consequently its effect on the intention to purchase online. Accordingly, this study attempts to investigate the factors that influence trust, and consequently on purchase intention among Malaysian teachers in an online environment. Specifically, this study attempts:

i. To examine the relationship between perceived usefulness and online trust

ii. To assess the relationship between perceived ease of use and online trust

iii. To evaluate the relationship between perceived reputation and online trust

iv. To determine the relationship between perceived security and online trust

v. To investigate the relationship between perceived privacy and online trust

vi. To examine the effect of online trust on online purchase intention

\section{Literature Review}

The online purchase transaction is often associated with electronic commerce (EC). Electronic commerce (EC) is viewed as a process in which products and services are sold and purchase online (Greenstein and Vasarhelyi, 2002). Turban, McLean, Wetherbe, and Leidner (2004) defined EC as the process of purchasing, selling, transferring or the exchange of products, services or information through computer networks including the Internet channel. From a business process viewpoint, EC refers to carrying out business electronically by completing 
business processes over electronic networks, while from the perspective of the service, EC refers to the tool that will reduce the service costs, upgrade the customer service and improve the speed of service delivery (Turban et al., 2004; Greenstein and Vasarhelyi, 2002). An EC involves two major components that is e-marketing and e-purchasing. Thus, in this study the investigation of online shopping is largely related the context of e-purchasing (Kotler and Armstrong, 2010).

Online shopping refers to process undertaken by customers to acquire services or products on the internet (Jiang, Yang, and Jun, 2013). Since online purchase involves internet network, customers can buy products or services at anytime and anywhere at the customer convenience. The use of internet in purchasing activities benefited both buyer and the seller, in which it eliminates the brick and mortar store purchase approach which often relates to the many problems such as time consuming and labour intensive. A recent study by Akbar and James (2014) further pointed out that online shopping could help the companies to upgrade their existing marketing system.

Online shopping among Malaysian has increased significantly. Azizah, Ramayah, Lin, Osman and Marimuthu (2011) stated that the use of internet application in the business transaction has converted the mode of companies' communication, the information sharing method with business partners and the manner of their buy and sell transaction. Chua, Ali and Hishamuddin (2006) revealed that since the introduction of the JARING, the first internet service provider (ISP) in Malaysia in the 1990, which later changed to TMNET in 1996, the usage of internet among Malaysian had increased significantly. With the introduction of the Multimedia Super Corridor (MSC) in 1996, the Information and Communication Technology (ICT) infrastructure has developed rapidly (Hashim, 2008).

Omar and Anas (2014) then highlighted that the government had worked hard to encourage the usage of internet among Malaysian and ensure the investment and development of ICT at all levels of the Malaysian community. In relation to that, the government had announced seven innovative flagship applications in orders to enhance of vision 2020, which is to transform Malaysia into a knowledge-based society. The seven innovative flagships developed in the MSC are to actualize a multimedia utopia for innovative producers and users in the field of multimedia technology. They are focused on the development of smart schools, Tele-health, e-Business, smart card technology, Research and Development (R\&D) clusters, electronic government and technopreneur development. With lots of incentives provided by the Malaysian government in expanding the usage of ICT among Malaysian community, improvement in computer literacy among Malaysians has increased dramatically. In particular, the internet is not only used for communication or online games, but for many other purposes, including for online shopping, where it indirectly increases the country's economic development.

\section{Technology Acceptance Model (TAM)}

The framework of this study was formulated by adapting Technology Acceptance Model (TAM) by Davis (1989) and the Extended TAM by Yaobin, Tao and Wang (Yaobin, Tao, and Wang, 2007). The Technology Acceptance Model (TAM) was originally developed in order to predict and explain the individual's acceptance of system usage. In the model, user acceptance/intention to use are determined by two factors, i.e. perceived usefulness and perceived ease of use, which perceived usefulness tend to be a stronger predictor than ease of use. Recently, many researchers have adapted TAM as guidance to formulate their research framework. The standard TAM has been modified by adding some new variables. For instance, Intana and Chansa-ngavej (2014) extended TAM to investigate the internet banking 
adoption by adding two variables, namely perceived privacy and normative belief. A recent study by Ye and Zhang (2014) on the impact of sales promotion on consumers' intention to purchase online in consumer-to-consumer (C2C) marketplace also added two external variables, which are sales promotion and perceived risk, to the basic TAM. In addition, Umair et al. (2012) and Rapidah et al. (2014) added perceived enjoyment as a third variable in TAM. Another study by Ubaid et al. (2013) has transformed the TAM into a complex model to comply with their research on electronic shopping. In particular, the study investigated the effect of electronic attitude, electronic enjoyment, electronic risk, electronic usefulness, electronic ease of use, electronic trust and electronic self-efficacy on the online shopping intention, which electronic attitude was revealed as the strongest predictors while electronic enjoyment as the weakest predictors of the intention to shop online. Another research that extended the TAM is Yaobin and Tao (2007), which highlighted that role of perceived ease of use, perceived reputation, perceived security, propensity to trust, perceived usefulness and consumers' initial trust to affect the online purchase intention among Chinese consumers. Comparing among all the extended TAM, it seems that Yaobin and Tao (2007) had offered a more comprehensive extended TAM in the online shopping context. Thus, in this study, the model was adopted.

Trust

Mayer, Davis and Schoorman $(1995,712)$ defined trust as "the willingness of a party to be vulnerable to the actions of another party based on the expectation that the other will perform a particular action important to the trustor, irrespective of the ability to monitor or control that other party". In relation to that, Rousseau, Sitkin, Burt and Camerer (1998) describes trust as a psychological condition that consists of the intention to accept vulnerability based on positive expectations of the intention and behaviour of the partner in a relationship. Furthermore, Kimery and McCord (2002) defined trust as the consumers' willingness to accept vulnerability based on their positive expectations about the future behaviour of sellers. In addition, Porter and Donthu (2011) defined trust as a belief that relates to benevolence, integrity and judgement. Benevolence is regarded as how genuinely interested and motivated a person towards a partner's welfare and to seek for maximum joint gain, integrity as an individual's perception to consistently comply with the acceptable principles of behaviour (Jarvenpaa and Leidner, 1998) and, judgement as a perception that the other party is able to make decisions in the interests of both parties in the relationship (Smith and Barclay, 1997). Accordingly, the trust can be defined as the ability to make yourself vulnerable to the actions taken by the reliable party based on a sense of confidence or assurance (Gefen 2002).

In a business context, trust is referred as the belief that the partner will act in a spirit of goodwill and in no way to harm the trustor (Hagen and Choe, 1998). Similarly, Grazioli and Jarvenpaa (2000) described trust as a person's belief that others will act according to person expectation. Further, they added that trustor, a consumer who has no knowledge beforehand, will rely on the information provided on the website in order to make a judgment of the seller's trustworthiness. Thus, whenever the seller has the ability to serve the customer with finest treatment, there are more likely for the customer to build trust on the seller (Ganesan, 1994). Specifically for the online business setting, trust is regarded as the willingness of a customer to rely on the seller with the expectation that the seller will act in the best way that will benefit both customer and seller (Jarvenpaa and Leidner 1998). Kim, Song, Braynov and Rao (2005) further indicated that trust towards the online stores is different from the brickand-mortar stores, in which trust in an internet business depends on transaction process, while trust in traditional stores depend on face-to-face interactions between buyer and seller. 
Besides, Teo and Liu (2007) revealed that online trust is built upon consumer attitudes to the sellers and their risk perceptions towards online transactions, while Schlosser, White and Lloyd (2006) emphasized on the role of belief and intention. In similar to trust in traditional relationships, trust in online environment does build up along with the progress of the customer relationship (Salo and Karjaluoto, 2007). Accordingly, in the context of this research, trust can be referred as the consumer's willingness to believe and depend on the online seller, which further will stand as prominent factors in influencing consumer's behaviour in online transaction activities.

\section{Determinants of Online Trust}

The role of trust has been widely discussed in various disciplines and context including the online purchase. Most of those studies had been directed to investigate the antecedents of trust (Gefen, 2002; Yaobin, Tao, and Wang, 2007; Choi, Choi, and Kim, 2012; Lee and Ahn, 2013; Zakaria and Ahmad, 2014). Many factors had been proven as significant determinants of online trust, which can be divided into internal and external factors (Salo\&Karjaluoto, 2007). In particular, the external factors are factors that may not have a direct relation to influence the formation of trust such as customer characteristics, the nature of the product and service, the development of the market, culture and countries, the customers perception of risk, and any other experience that the customer has had dealing with sales and marketers; whereas internal factors are factors that closely related to a given online service such as customers prior experience with web vendors, the web vendor's trustworthiness and reputation, the quality of the web site, the acceptance of the information system, third party trust, and the company's online privacy policy. Comparing between these two categories of trust determinants, it is apparent that most of the past studies have been focusing on examining the effect of internal factors than the external factors (Yaobin, Tao, and Wang, 2007; Zakaria and Ahmad, 2014; Wang and Shan, 2013; Broutsou, 2012).

\section{Perceived Usefulness}

Perceived usefulness has been defined by Davis (1989) as the extent to which a person perceives that using a particular system would improve his/her work performance. It is believed that a system with high level of perceived usefulness could induce the user trust in the presence of a positive relationship. In support of the statement, findings of past studies highlighted that perceived usefulness has a significant positive effect on online trust (Gefen, 2002; Yaobin, Tao, and Wang, 2007; Choi, Choi, and Kim, 2012; Fakhraddin, Fatemah, and Marzieh, 2013; Kaihong, 2012). Moreover, it was revealed that perceived usefulness is among the strongest predictor to affect trust (Choi, Choi, and Kim, 2012). However, Fatah, Saeed and Amir (2011) pointed out a contradict result, indicated that the perceived usefulness has no significant effects on consumer trust in online shopping. Despite the contradict results, given the majority findings that support on the positive and significant relationship between perceived usefulness and online trust, it could be hypothesized that:

\section{H1: There is a positive relationship between perceived usefulness and online trust.}

\section{Perceived Ease of Use}

Perceived ease of use refers to the extent to which service systems provided are considered as easy to understand and operate (Rose and Fogarty 2010). In the online shopping setting, Lee, Park and Ahn (2000) described the perceived ease of use as the convenience to seek for 
information, ordering and get the customer service. In addition, Gefen, Karahanna and Straub (2003) defined perceived ease of use as the level of the cognitive effort that is required to learn and use the technology. Further, the findings showed that perceived ease of use promotes experienced consumer to repeat their purchase with the existing online sellers. From the findings, it is apparent that perceived ease of use does have a positive impact on consumer trust. The results seem to be in line with Lee and Ahn (2013) and Fakhraddin et al. (2013), which found out that perceived ease of use has a significant positive effect toward trust.Another study by Seyed, et al. (2011) revealed ease of use is the main predictor of trust. Thus, it could be believed that a strong positive relationship between perceived ease of use and online trust. Therefore, it could be hypothesized that:

\section{H2: There is a positive relationship between perceived ease of use and online trust.}

\section{Perceived Reputation}

Reputation refers to the extent to which the consumers perceive that the store has a sense of honesty and concerns about the consumers benevolence (Doney and Cannon, 1997). The findings of the prior studies pointed out that the online seller with a good reputation are seen as a trustworthy individual (Jarvenpaa, Tractinsky, and Saarinen, 1999; McKnight, Cummings, and Chervany, 1998). A study by Van der Heijden, Verhagen, \&Creemers (2003) provided that perceived reputation has a positive impact on customer trust, but only for cheaper product such as books and CDs, not for expensive product like flight ticket. The study by Friedman, Khan and Howe (2000) further pointed out that technology features are more likely to build a reputation, which in turn enhance the trust among new technology user. In addition, Walczuch and Lundgren (2004) revealed perceived reputation as the main determinants of consumers trust, but Yaobin and Tao (2007) found out that reputation does affect trust, but the impact is relatively weak. Recent studies also demonstrated a significant positive relationship between reputation and trust (Broutsou, 2012; Davis, Sajtos, and Chaudhri, 2011; Fatah, Saeed, and Amir, 2011). However, Prompongsatorn, Sakthong, Chaipoopirutana, and Combs (2012) demonstrated that there is no relationship between consumers' perception of reputation and consumers' trust in internet shopping in Thailand. Despite the contradict results, the majority of the findings support on the positive and significant relationship between perceived reputation and online trust. Therefore, it could be hypothesized that:

\section{H3: There is a positive relationship between perceived reputation and online trust.}

\section{Perceived Security}

According to Hsu, Liu, and Lee (2010), perceived security is the perception of consumers on the degree of protection against transaction threats that may occur due to unauthorized access to the account. In order to avoid threats, the security controls over the customers' account should be enhanced. In relation to that, it has been found that perceived security is a significant factor that influence on initial trust in online stores (Ganguly, Dash, and Cyr, 2009; Yaobin, Tao, and Wang, 2007). Consumers hold a strong belief about the safety and privacy issues, that they tend to trust only the sites that can secure their personal and financial information (Dolatabadi and Ebrahimi, 2010). However, according to the recent studies, perceived security has a weak significant impact (Zakaria and Ahmad, 2014) or even insignificant effect on trust the relationship (Zakaria and Ahmad, 2014; Prompongsatorn et 
al., 2012). Despite the recent findings on the insignificant effect of perceived security, given the majority findings emphasizing the positive effect, it could be expected in this study of the significant effect of perceived security on online trust. Therefore, it could be hypothesized that:

\section{H4: There is a positive relationship between perceived security and online trust.}

\section{Perceived Privacy}

Hsu, et al. (2010) defined perceived privacy as the readiness of consumers to expose their personal information through the internet medium that allows purchases to be conducted, while Dinev, $\mathrm{Xu}$, Smith, and Hart (2013) referred perceived privacy as an individual's selfassessed state in which external agents have limited access to information about him or her. Pavlou (2001) indicated that perceived privacy influences trust among consumers in electronic commerce (EC). The findings were supported by the current study of (Davis, Sajtos, and Chaudhri, 2011), which shown that perceived privacy has a significant impact on consumers trust. Furthermore, Wang and Shan (2013) indicated that consumers' perception of privacy protection contributes positively to the formation of consumers' trust in mobile banking, but Prompongsatorn et al. (2012) provided a contradict results, highlighting that there is no relationship between consumers' perception of privacy and consumers' trust in internet shopping in Thailand. Taking into account of the majority findings, it could be hypothesized that:

\section{H5: There is a positive relationship between perceived privacy and online trust.}

\section{Relationship between Trust and Online Purchase Intention}

Pavlou (2003) described online purchase intention as the extent to which the consumer is willing to engage in an online transaction, while. George (2004) regarded the online purchase intention as the customers' readiness to browse, choose and buy products using the internet facilities. Besides, Mohd Sam and Tahir (2009) defined online purchase intention as the likelihood of a customer to acquire the products online, while Fatemah, Zurani and Shanmugam (2013) referred online purchase intention as customer desires to purchase via internet.

Much research had emphasized on the significant relationship between trust and the customers online purchase intention (Pavlou, 2003; Ganguly, Dash, and Cyr, 2009; George, 2004; Kim, Chung, and Lee 2011; Fatemah, Zurani, and Shanmugam 2013). In particular, Jarvenpaa et al. (1999) also found out that trust enhances the willingness to shop online. According to Nah and Davis (2002), customer intention to purchase product via online medium is due to the trust factor. Such findings were supported by Pavlou (2003) and George (2004), which highlighted a direct positive relationship between trust and intention to purchase. In addition, it had been revealed that the most paramount predictor of online intention to purchase is trust (Fatemah, Zurani, and Shanmugam 2013; Ganguly, Dash, and Cyr 2009; Hossein, Seyede, and Faeze 2011; Kim, Chung, and Lee 2011; Mohd Sam and Tahir 2009). Futher, Ling, Dazmin, Piew, Keoy and Padzil (Ling et al., 2011) found a significant positive between trust and online purchase intention in Malaysia. The recent studies by Kaihong (2012), Lee and Ahn (2013) and Seyed et al. (2013) also demonstrated that consumer trust has a significant positive effect toward the online purchase intention. Accordingly, the following hypothesis was proposed: 
H6: There is a positive relationship between online trust and online purchase intention

Based on the proceeded hypotheses, the following model is proposed.

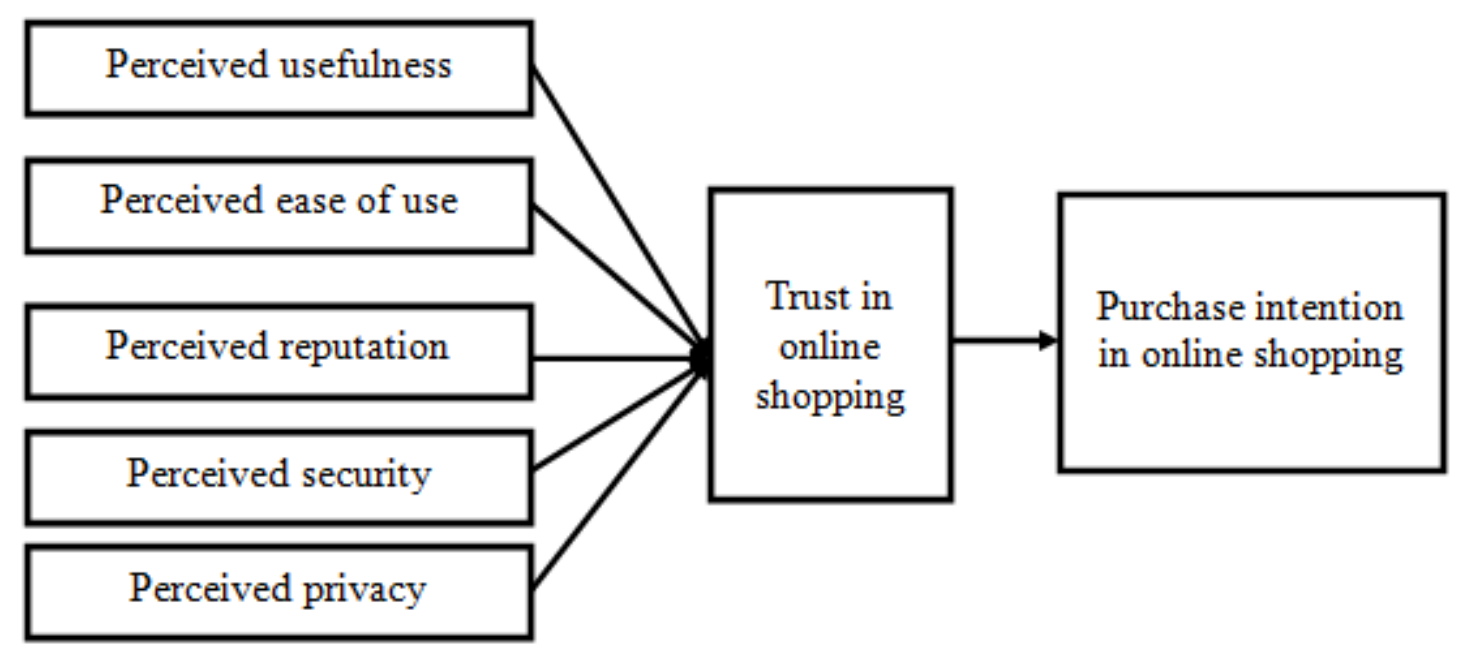

Figure 3 Proposed Framework

\section{Methodology}

This study adopted a quantitative approach and descriptive in nature. A convenience sampling technique was used to gather data from a sample, which consist of 150 primary school teachers. The sample size was considered sufficient as it satisfy the recommended sample size for conducting Multiple Regression (Chua, 2013; Coakes and Steed, 2003; Ho, 2006).Pilot tests were undertaken on 66 respondents before the actual survey in order to check on the readability and clarity of the questions as well as to test on the validity and reliability of the instrument. The output of Exploratory Factor Analysis showed the Kaiser-Mayer-Olkin (KMO) statistic values ranging from 0.726 to 0.866 with significant Bartlett Test of Sphericity values, indicating the adequacy to proceed with factor analysis (Huck, 2012; Pallant, 2007; Tabachnick and Fidell, 2007). With Total Variance Explained and factor loadings above a threshold of $60 \%$ and 0.5, respectively (Hair et al. 2010), the measurement items for all constructs were confirmed. Thus, the validity is achieved. The output of the reliability test showed the Cronbach's alpha values within the range of 0.768 and 0.894 , indicating an acceptable scale with respect to reliability. Data for actual study were analysed using descriptive and inferential statistics. Descriptive statistics involve frequency analysis to describe the profile of the respondents and reliability analysis. Inferential statistics involve multiple regression analysis, which used to test the proposed hypotheses.

\section{Results}

\section{Profile of Respondents}

The sample for this study consists of 150 respondents, with a valid data of 113 (37 responses were excluded due to the responses have either more than 10 percent of unanswered items or the same answer to all questions). Most of the respondents are female $(70.8 \%)$, in the age range 
of 30 to 39 years old (46.9\%), Malay (87.6\%) and have undergraduate education $(61.1 \%)$. Screening of the data shows no missing values. More than half of the respondents reported that they earn between RM4001 and RM6000 per month (58.4 percent) and most of them in the of grade DG41/42 (46 percent). The majority of the respondents were online shopper $(74.3 \%)$, which most of them spend at least one to two hours online $(52.3 \%)$, had purchased online one to three times in the last six months $(62.8 \%)$, purchased clothes $(33.7 \%)$ and had spent below RM250 per purchase (45.9\%).

\section{Results of Multiple Regression Analysis}

The assumptions of Multiple Regression i.e. normality, outliers and multicollinearity were first checked. The skewness and kurtosis values are in the range of \pm 2 (Garson, 2012), which satisfy the normality assumption. The box plots show no extreme cases, which indicating no univariate as well as multivariate outliers (Coakes\& Steed, 2003). Further, the variance inflation factor (VIF) values for independent variables are less than 3.0, which is well below the recommended upper limit of 10 (Hair et al., 2010) with minimum tolerance of 0.315 , which above the threshold of 0.2 (Garson, 2012). Therefore, multicollinearity problem does not appear to influence the results. As no significant violation is found, the data is suitable for further analysis.

Table 3 presents the results of the regression analysis. For the first equation, the results show that perceived usefulness, perceived ease of use, perceived reputation, perceived security and perceived privacy are able to explain 68.1 percent of the variance in online trust, significant at 0.001 level. However, only perceived ease of use, perceived security and perceived privacy have a positive and significant effect on online trust. With a beta coefficient of 0.352 , perceived ease of use turns out to be the strongest predictor. Therefore, $\mathrm{H} 2, \mathrm{H} 4$ and $\mathrm{H} 5$ are supported, while $\mathrm{H} 1$ and $\mathrm{H} 3$ are not supported.

For the second equation, the results show that online trust explains 56.6 percent of the variation in the online purchase intention. Furthermore, the results reveal the positive and significant effect of online trust on online purchase intention. Hence, H6 is supported.

Table 3 Multiple Regression Output

\begin{tabular}{|c|c|c|}
\hline & Online Trust & Online Purchase Intention \\
\hline$R$ & 0.825 & 0.753 \\
\hline$R^{2}$ & 0.681 & 0.566 \\
\hline Adjusted $R^{2}$ & 0.672 & 0.562 \\
\hline Std.Error of the Estimate & 1.918 & 2.327 \\
\hline$F$ & $72.727^{\star \star *}$ & $142.421^{* * *}$ \\
\hline \multicolumn{3}{|l|}{ Perceived Usefulness } \\
\hline Standardised coefficient & $-0.108^{n s}$ & \\
\hline \multicolumn{3}{|l|}{ Perceived Ease of Use } \\
\hline Standardised coefficient & $0.352^{* * *}$ & \\
\hline \multicolumn{3}{|l|}{ Perceived Reputation } \\
\hline Standardised coefficient & $0.118^{\mathrm{ns}}$ & \\
\hline \multicolumn{3}{|l|}{ Perceived Security } \\
\hline Standardised coefficient & $0.343^{* * *}$ & \\
\hline \multicolumn{3}{|l|}{ Perceived Privacy } \\
\hline Standardised coefficient & $0.269^{* * *}$ & \\
\hline \multicolumn{3}{|l|}{ Online Trust } \\
\hline Standardised coefficient & $0.175^{* *}$ & $0.753^{* * *}$ \\
\hline
\end{tabular}




\section{Discussion, Implication and Limitation}

This study aims to investigate the factors that influence consumer trust in online shopping among school teacher, which in turn affect the purchase intention. Table 4 summarizes the hypothesis testing results.

Table 4 Hypothesis Testing Results

\begin{tabular}{|l|c|}
\hline \multicolumn{1}{|c|}{ Hypothesis } & Results \\
\hline $\begin{array}{l}\text { H: There is a positive relationship between perceived usefulness and online } \\
\text { trust. }\end{array}$ & Not Supported \\
\hline $\begin{array}{l}\text { H2: There is a positive relationship between perceived ease of use and online } \\
\text { trust. }\end{array}$ & Supported \\
\hline $\begin{array}{l}\text { H3: There is a positive relationship between perceived reputation and online } \\
\text { trust. }\end{array}$ & Not Supported \\
\hline $\begin{array}{l}\text { H4: There is a positive relationship between perceived security and online } \\
\text { trust. }\end{array}$ & Supported \\
\hline $\begin{array}{l}\text { H5: There is a positive relationship between perceived privacy and online trust. } \\
\text { H6: There is a positive relationship between online trust and online purchase } \\
\text { intention. }\end{array}$ & Supported \\
\hline
\end{tabular}

The results reveal a significant positive relationship between perceived ease of use and teacher's trust in online shopping. The findings supported the past research by Lee and Ahn (2013), Gefen et al. (2003), Seyed et al. (2011) and Fakhraddin et al. (2013). This implies that when the online seller provide convenience website platform, teachers are more likely to become attracted to online sales, increase their confidence toward online seller and willing to engage in online purchasing more frequently.

The perceived security has a significant positive relationship towards teacher's trust in online shopping activities. The findings of this research seem to differ with the findings of the prior research by Prompongsatorn et al. (2012) and Zakaria and Ahmad (2014), but support the past research by Pavlou (2001), Yaobin and Tao (2007), Ganguly et al. (2009) and Dolatabadi and Ebrahimi (2010). Hence, the results indicate that teachers are more likely to trust when the online seller employ security systems as to protect their customers.

Perceived privacy has a significant positive relationship towards teacher's trust in online shopping activities. Despite the results are inconsistent with Prompongsatorn et al. (2012), they support the findings by Pavlou (2001), Davis et al. (2011) and Wang and Shan (2013). Thus, the findings imply that when an online seller assures consumer confidentiality, customers are more likely to trust the seller.

The perceived usefulness has no significant impact on online trust activities. The results support the previous research by Fatah et al. (2011), but seem to contradict with other studies such as Gefen (2002), Yaobin and Tao (2007), Choi et al. (2012), Kaihong (2012) and Fakhraddin et al. (2013). The possible explanation for this finding could be teachers tend to purchase online occasionally and be more attracted to the cheapest offer. As long as they can find the cheapest offer, they are more likely to purchase online. Thus, the usefulness of the online shopping might play no roles to trigger trust among teachers. 
The perceived reputation also has no significant effect toward online trust. The findings are in line with the finding by Yaobin and Tao (2007) as well as Prompongsatorn et al. (2012) but in contrast with McKnight et al. (1998), Jarvenpaa et al. (1999), Heijden et al. (2000), Friedman et al. (2000), Walczuch and Lundgren (2004), Davis et al. (2011), Fatah et al. (2011), and Broutsou and Fitsilis (2012). This may be due to the Malaysian culture that easily trust anyone. They always have faith for everyone and do not feel necessary to check out for someone's reputation.

Finally, the results demonstrate that online trust has a significant positive relationship with online purchase intention.The findings of this study supported Ling et al. (2011), Kaihong (2012), Lee and Ahn (2013) and Seyed et al. (2013). Thus, the results explain that when teachers have a high level of trust, they are more likely to engage in online shopping activities.

\section{Implications}

This research contributes to the existing literature by providing empirical evidence on the significant effect of perceived ease of use, perceived security and perceived privacy on online trust and consequently on the online purchase intention. Besides, this study highlights the applicability of the extended Technology Acceptance Model (TAM) to investigate the trust and purchase intention in the online shopping context. In addition, the findings provide useful insights to the online seller on how they can gain consumer trust and trigger consumer intention to purchase, particularly among teachers. Given that the population of teachers is enormous, the findings could help the sellers on how they can penetrate the huge market of teachers and make profits. Finally, the finding point out critical elements that sellers should take into account in designing their websites in order to attract and engage the customers.

\section{Limitation}

There are several limitations to this study. First, the research was conducted on a small scale and employed a convenience sampling method. Thus, the findings may not represent the perspective of the primary school teachers nationwide and should be generalized with caution. Second, this study employed multiple regression instead Structural Equation Model (SEM). Hence, the accuracy of the finding may be slightly affected. Therefore, future research should always consider using SEM. Third, this study had ignored several antecedents that might be relevant to affect online trust and purchase intention such as perceived size, perceived enjoyment, perceives risk, perceived experience, individualistic cultures, structure assurance, situation normality and service quality. Therefore, future research might want to examine these factors in order to increase the explanatory power of the framework.

\section{References}

Akbar, S., \& James, P.T.J. (2014). Consumers' attitude towards online shopping factors influencing employees of crazy domains to shop online. Journal of Management and Marketing Research, 14, 1-11.

Azizah, O., Ramayah, T., Lim, B.L., \& Mohamad, O.\& Marimuthu, M. (2011). Determining factors for the usage of web-based marketing applications by small and medium enterprises (SMEs) in Malaysia. Journal of Marketing Development and Competitiveness, 5(2), 70-86.

Bernama. (2014). Malaysians love to shop online. Retrieved fromhttp://www.therakyatpost.com/life/2014/07/08/malaysians-love-shop-online/

Broutsou, A., \& Fitsilis, P. (2012). Online trust: The influence of perceived company's reputation on consumers' trust and the effects of trust on intention for online transactions. Journal of Service Science and Management, 5(1), 365-372. 
Chai, L.T., Hong, Y.K., \& Ching, C.C. (2010). Exploring Malaysian trainee teachers' adoption of the internet as information tool. International Journal of Instruction, 3(2), 25-38.

CheMohd, Z. \& Anas, T. (2014). E-commerce in Malaysia: Development, implementation and challenges. International Review of Management and Business Research, 3(1), 291-298.

Choi, H., Choi Y.J., \& Kim, K.M. (2012). The understanding of building trust model on smartphone application: focusing on users' motivation, presented at Proceedings of the International Conference on IT Convergence and Security, 2011.

Chua, A.P.H., Ali, K. \& Hishamuddin, I. (2006). E-commerce: A study on online shopping in Malaysia. Journal of Social Science, 13(3), 231-242.

Chua, Y.P. (2013). Mastering Research Statistics. Shah Alam, Selangor: McGraw-Hill Education.

Coakes, Sheridan, J., \& Lyndall, G.S. (2003). SPSS analysis without anguish: Version 11.0 for windows. Queensland: John Wiley \& Sons Australia Ltd.

Davis, F.D. (1989). Perceived usefulness, perceives ease of use, and user acceptance of information technology. MIS Quarterly, 13(3), 319-340.

Davis, Sajtos, R.L., \& Chaudhri, A.A. (2011). Do consumers trust mobile service advertising? Contemporary Management Research, 7(4), 245-270.

Dinev, T.,Xu, H., Smith, J.H., \& Hart, P. (2013). Information privacy and correlates: An empirical attempt to bridge and distinguish privacy-related concepts. European Journal of Information Systems, 22(3), 295-316.

Dolatabadi, H.R., \& Ebrahimi, H. (2010). Factors influencing Iranian consumers' trust in internet shopping. European Journal of Social Sciences, 16(2), 307-318.

Doney, P.M., \& Cannon, J.P. (1997). An examination of the nature of trust in buyer-seller relationships. The Journal of Marketing, 35-51.

Fakhraddin, M., Fatemah, K., \& Marzieh, D. (2013). An investigation of initial trust in mobile banking. International Journal of Academic Research in Business and Social Sciences, 3(9), 394-403.

Fatah, A.A., Saeed, F., \& Amir, P. (2011). Factors affecting the attitude of trust in internet purchasing from the perspective of consumers. Interdisciplinary Journal of Contemporary Research in Business, 3(5), 208-221.

Fatemah, M., Zurani, I., \& Shanmugam, B. (2013). Online purchase intention: Effects of trust and security perception. Australian Journal of Basic and Applied Sciences, 7(6), 307-315.

Friedman, B., Khan, P.H. \& Daniel, C.H. (2000). Trust online. Communications of the ACM, 43(12), 34-40.

Ganesan, S. (1994). Determinants of long-term orientation in buyer-seller relationships. Journal of Marketing, 58(2), 1-19.

Ganguly, B., Dash, S.B., \& Cyr, D. (2009). Website characteristics, trust and purchase intention in online stores: An Empirical study in the Indian context. Journal of Information Science and Technology, 6(2), 22-44.

Garson, G.D. (2012). Testing Statistical Assumptions, Blue Book Series. Asheboro, USA: Statistical Associates Publishing.

Gefen, D. (2002). Customer loyalty in e-commerce. Journal of the Association for Information Systems, 3(1), $27-51$.

Gefen, D., Karahanna, E., \& Straub, D.W. (2003). Trust and TAM in online shopping: An integrated model. MIS Quarterly, 27(1), 51-90.

George, J.F. (2004). The theory of planned behavior and internet purchasing. Internet research, 14(3), 198-212.

Grazioli, S., \& Jarvenpaa, S.L. (2000). Perils of Internet fraud: An empirical investigation of deception and trust with experienced Internet consumers. IEEE Transactions on Systems, Man and Cybernetics, Part A: Systems and Humans, 30(4), 395-410.doi:10.1109/3468.852434

Greenstein, M., \& Vasarhelyi, M.A. (2002). Electronic Commerce: Security, Risk Management, and Control. New York, USA: McGraw-Hill/Irwin.

Hair, J.F., Black, W.C., Babin, B.J., \& Anderson, R.E. (2010).Multivariate Data Analysis: A global perspective (7th edition).Upper Saddle River, New Jersey: Pearson Education Inc.

Hashim \& Junaidah. (2008). Factors influencing the acceptance of web- based training in Malaysia: Applying the technology acceptance model. International Journal of Training and Development, 12(4), 253-264.

Ho, R. (2006). Handbook of Univariate and Multivariate Data Analysis and Interpretation with SPSS. Boca Raton, Florida: Chapman \& Hall/CRC (Taylor \& Francis Group).

Hossein, R.D.A., Seyede, N.A.H., \&Faeze, K.Z. (2011). Considering factors that affect users' online purchase intentions with using structural equation modelling. Interdisciplinary Journal of Contemporary Research in Business, 3(8), 463-471.

Hsu, C.L., Chia, C.L., \& Lee, Y.D. (2010). Effect of commitment and trust towards micro-blogs on consumer behavioural intention: A relationship marketing perspective. International Journal of Electronic Business Management, 8(4), 292-303.

Huck, S.W. (2012). Reading Statistics and Research (6th edition). Boston, MA: Pearson Education Inc.

Intana, M., \& Chansa-ngavej, C. (2014). An extended technology acceptance model for internet banking adoption. Asian Journal of Management Research, 5(1), 124-137.

Jarvenpaa, S.L.,\& Leidner, D.E. (1998). Communication and trust in global virtual teams. Journal of ComputerMediated Communication, 3(4). 
Jarvenpaa, S.L., Tractinsky, N., Saarinen, L. (1999). Consumer trust in an internet store: A cross- cultural validation. Journal of Computer- Mediated Communication, 5(2).

Jasman, J.M., Osman, M., \& Ramayah, T. (2005). Intention to purchase via the internet: A comparison of two theoretical models. Asian Academy of Journal, 10(1), 79-95.

Jiang, L., Yang, Z., \& Jun, M. (2013). Measuring consumer perceptions of online shopping convenience. Journal of Service Management, 24(2), 191-214.

Xiao, K.H. (2012). An empirical study of consumer's E-commerce initial trust antecedents. International Journal of Advancements in Computing Technology, 4(18), 559-567.

Kim, D.J., Song, Y.I., Braynov, S.B., \& Rao, H.R. (2005). A multidimensional trust formation model in B-to-C ecommerce: A conceptual framework and content analyses of academia/practitioner perspectives. Decision Support Systems, 40(2), 143-165.

Kim, M.J., Chung, N., \& Lee, C.K. (2011). The effect of perceived trust on electronic commerce: Shopping online for tourism products and services in South Korea. Tourism Management, 3(2), 256-265.

Kimery, K.M., \& McCord, M. (2002). Third-party assurances: Mapping the road to trust in e-retailing. JITTA: Journal of Information Technology Theory and Application, 4(2), 63.

Kotler, P., \& Armstrong, G. (2010). Principles of Marketing13th edition. Singapore: Pearson Education International.

Lee, D., Park, J., \&Ahn, J. (2001). On the explanation of factors affecting e-commerce adoption, proceeding of the International Conference in Information Systems.

Lee, H.Y., \& Ahn, H. (2013). The role of trust in the adoption of mobile commerce: Comparison to the adoption of e-commerce. Journal of Convergence Information Technology, 8(18), 136-147.

Leng, J., \& Zhang, T. (2012). The influencing factors of customer trust to great discount online shops: Based on the Chinese Market. Retrieved from http://urn.kb.se/resolve?urn=urn\%3Anbn\%3Ase\%3Auu\%3Adiva-205325

Li, Y.H., \& Huang, J.W. (2009). Applying theory of perceived risk and technology acceptance model in the online shopping channel. World Academy of Science, Engineering and Technology, 53(1), 919-925.

Lim, W.M., \& Ting, D.H. (2012). E-shopping: An analysis of the technology acceptance model. Canadian Center of Science and Education, 6(4), 49-62.

Ling, K.C., Dazmin, D., Piew, T.H., Keoy, K.H., \& Padzil, H. (2011). Perceived risk, perceived technology, online trust for the online purchase intention in Malaysia. International Journal of Business and Management, 6(6), 167182.

Malaysia tutors consultancy: Malaysian tution rate. (2015). Retrieved from http://malaysiatutors.com/malaysiatuition-fee-guidelines/.

Marzieh, Z., Laily, P., Jamil, B., \& Syuhaily, B. (2011). The effects of trust on online Malaysian students buying behavior. Australian Journal of Basic and Applied Sciences, 5(12), 1125-1132.

Mayer, R.C., Davis, H.H., Schoorman, F.D. (1995). An integrative model of organizational trust. Academy of Management Review, 20(3), 709-734.

McKnight, D.H., Cummings, L.L. \& Chervany, N.L. (1998). Initial trust formation in new organizational relationships. Academy of Management Review, 23(3), 473-490.

Ministry of Education (EMIS). (2014). Higher Education Statistics: Number of teachers based on primary and secondary levels. Retrieved from http://www.moe.gov.my.

Ministry of Finance Malaysia. (2014). Economic Performance and Prospects: Economic Report 2013/2014. Kuala Lumpur: Government Printing Office.

Mohd Sam Mohd Fazli, \& Md Nor Hayati Tahir. (2009). Website quality and consumer online purchase intention of air ticket. International Journal of Basic and Applied Sciences, 9(10).

Nadaraj, V. (2013). The Establishment Post: Malaysians spend US\$354 on online shopping. Retrieved from http:/ / www.establishmentpost.com.

Nah, F.F.H., \& Davis, S. (2002). HCI research issues in e-commerce. Journal of Electronic Commerce Research, 3(3), 98113.

Pallant, J. (2007). SPSS Survival Manual: A step-by-step guide to data analysis using SPSS for Windows (3rd ed.). New York: Open University Press.

Pavlou, P. (2001). Consumer intentions to adopt electronic commerce-incorporating trust and risk in the technology acceptance model. DIGIT 2001 Proceedings. 2. Retrieved from http://aisel.aisnet.org/digit2001/2

Pavlou, P.A. (2003). Consumer acceptance of electronic commerce: Integrating trust and risk with the technology acceptance model. International Journal of Electronic Commerce, 7(3), 101-134.

Porter, Constance, E., Naveen, D., William H.MacElroy., \& Donna, W. (2011). How to foster and sustain engagement in virtual communities. California Management Review, 53(4), 80-100.

Prompongsatorn, C., Sakthong, N., Chaipoopirutana, S., \& Combs, H. (2012). The factors influencing consumer trust of internet shopping in Thailand. Paper presented at the Proceedings of ASBBS, 19(1), 736-745.

Rapidah, O.A., Azreen, A.G., Shafini, M.S., Haslina, C.N., \& Fadilah, A.S. (2014). Internet shopping in Malaysia: TAM model adoption. Journal of Basic and Applied Scientific Research, 4(3).

Rose, J., \& Fogarty, G. (2010). Technology readiness and segmentation profile of mature consumers, presented at Proceedings of the 4 th Biennial Conference of the Academy of World Business, Marketing and Management 
Development.

Rousseau, D.M., Sitkin, S.B., Burt, R.S., \& Camerer, C. (1998). Not so different after all: A cross-discipline view of trust. Academy of Management Review, 23(3), 393-404.

Salo, J., \& Karjaluoto, H. (2007). A conceptual model of trust in the online environment. Online Information Review, 31(5), 604-621.

Schlosser, A.E., White, T.B., Lloyd, S.M. (2006). Converting web site visitors into buyers: How web site investment increases consumer trusting beliefs and online purchase intentions. Journal of Marketing, 70(2), 133-148.

Seyed, F.A.A., Amir, P., \& Saeed, F. (2011). An analysis of factors affecting the consumer's attitude of trust and their impact on internet pushing behavior. International Journal of Business and Social Science, 2(23), 147-158.

Smith, J.B., \& Barclay, D.W. (1997). The effects of organizational differences and trust on the effectiveness of selling partner relationships. Journal of Marketing, 61(1), 3-21.

Tabachnick, B.G., \& Fidell, L.S. (2007). Using Multivariate Statistics. (5 ${ }^{\text {th }}$ ed.). Boston, MA: Pearson Education Inc.

Teo, T.S.H., \&Liu, J. (2007). Consumer trust in e-commerce in the United States, Singapore and China. Omega, 35(1), 22-38.

Turban, E., McLean, E., Wetherbe, J., \& Leidner, D. (2006). Information Technology for Management: Transforming Organizations in the Digital Economy. USA: John Wiley \& Sons.

UbaidRehman, Muhammad Rizwan, Affan Ahmed, Naeem Ali, \& Muhammad Hassan Khan. (2013). E-TAM model: A comprehensive approach to understand the adoption of electronic shopping. Journal of Basic and Applied Scientific Research, 3(11), 178-188.

Umair, C., Ridzwan, J., Faiza, D., \& Nawal, S. (2012). The trend of online shopping in 21st century: Impact of enjoyment in TAM model. Asian Journal of Empirical Research, 3(2), 131-141.

van der Heijden, Hans., Verhagen, T., \& Creemers, M. (2003). Understanding online purchase intentions: Contributions from technology and trust perspectives. European Journal of Information Systems, 12(1), 41-48.

Walczuch, R., \& Lundgren, H. (2004). Psychological antecedents of institution-based consumer trust in e-retailing. Information \& Management, 42(1), 159-177.

Wang, B., \& Shan, C. (2013). The effect of online to mobile trust transfer on the foundation of mobile banking trust. Journal of Communications and Network, 5(1), 112-115.

Lu, Y.B., Zhou, T., \& Bin, W. (2007). A comparison of prices in electronic markets and traditional markets of China. Chinese Economy, 40(5), 67-83.

Ye, L.R., \& Zhang, H.H. (2014). Sales promotion and purchasing intention: Applying the technology acceptance model in consumer-to-consumer marketplaces. International Journal of Business, Humanities and Technology, $4(3), 1-5$.

Zakaria Saleh., \& Ahmad Mashour. (2014). Consumer attitude toward m-commerce: The perceived level of security and the role of trust. Journal of Emerging Trends in Computing and Information Sciences, 5(2), 111-117. 